\title{
Interação entre tópicas musicais e o esquema harmônico le-sol-fi-sol na Missa de Réquiem (1816) de Marcos Portugal
}

\section{Interaction between musical topics and the le-sol-fi-sol harmonic schema in marcos portugal's requiem mass (1816)}

\author{
(iD) Ágata Yozhiyoka Almeida ${ }^{1}$ \\ (Universidade de São Paulo, São Paulo, Brasil) \\ agata.almeida@usp.br \\ iD Diósnio Machado Neto² \\ (Universidade de São Paulo, São Paulo, Brasil) \\ dmneto@usp.br
}

\begin{abstract}
Resumo: As tópicas musicais e os esquemas de contraponto galantes são considerados ferramentas para a análise do processo de significação da música setecentista, ainda que não sejam, necessariamente, articuladas entre si. Este artigo intenta observar, em um primeiro momento, como a interação dessas duas vertentes analíticas pode potencializar as estruturas simbólicas expressivas e lexicais que constituem os discursos musicais do século XVIII. Em seguida, propomo-nos a observar como tais interações ocorrem no discurso musical fúnebre da Missa de Réquiem (1816) de Marcos Portugal. Notamos que, nesse réquiem, a interação entre um esquema galante específico, o le-sol-fi-sol, ocorre tanto com
\end{abstract}

\footnotetext{
1 Mestre em Música (Musicologia) pela Escola de Comunicações e Artes da Universidade de São Paulo (ECA-USP) e graduada em Ed. Artística com Habilitação em Música pela Faculdade de Filosofia, Ciências e Letras de Ribeirão Preto da Universidade de São Paulo (FFCLRP-USP). Desenvolve pesquisas sobre Teoria Tópica, Significação Musical e Discurso Musical na música lusobrasileira dos séculos XVIII e XIX. Está vinculada ao Grupo de Pesquisa em Estudos Musicológicos e participa das atividades realizadas pelo Laboratório de Musicologia (LAMUS/EACH-USP), coordenados pelo Prof. Dr. Diósnio Machado Neto. Atualmente é doutoranda em Música (Musicologia) pela Universidade de São Paulo (ECA-USP) e graduanda em Filosofia (Bacharel) pela Universidade Federal Fluminense (UFF). Atua profissionalmente como Professora Estatutária de Arte na Fundação Municipal de Educação de Niterói.

2 Professor Livre-Docente da Escola de Artes, Ciências e Humanidades da Universidade de São Paulo (EACH-USP). É professor do programa de Pós-Graduação em Musicologia do Departamento de Música da ECA-USP, onde ministra as disciplinas de Análise da Historiografia Musical Brasileira e Estudos de Significação Musical e do Programa de Pós-Graduação em Mudança Social e Participação Política (PROMUSPP) da EACH-USP. Professor Convidado do Magíster en Musicología Latinoamericana da Universidad Alberto Hurtado (Chile). Possui graduação em Bacharel em Música - Habilitação Instrumento - pela Pontificia Universidad Catolica de Chile (1992), mestrado e doutorado em Musicologia pela Universidade de São Paulo (2001; 2008), tendo como orientadores José Eduardo Martins (mestrado) e Mário Ficarelli (doutorado)
} 
a tópica ombra, tal como proposto e observado por Byros (2014), como também com as tópicas tempesta e o estilo eclesiástico.

Palavras-chave: Morte; Réquiem; Teoria tópica; Esquemas de contraponto galantes.

Abstract: Both musical topics and galant schemata are considered tools for the analysis of the signification process of the eighteenth-century music, even though they are not necessarily articulated with each other. The aim of this paper is to observe, at first, how the interaction of these two analytical perspectives enhance the expressive and lexical symbolic structures that constitute the eighteenth-century musical discourses. Then, we propose to observe how these interactions occur in the funereal musical discourse of Marcos Portugal's Requiem Mass (1816). We have noticed that, in this requiem, the interaction between a specific galant schema, the le-sol-fi-sol, occurs with ombra topic, as proposed and studied by Byros (2014), as well as with tempesta and learned style topics.

Keywords: Death; Requiem; Topic theory; Galant schemata.

Submetido em: 17 de novembro de 2019

Aprovado em: 27 de novembro de 2020 
Interação entre tópicas musicais e o esquema harmônico le-sol-fi-sol na Missa de Réquiem... Ágata Yozhiyoka Almeida. Diósnio Machado Neto

\section{Introdução}

Recentes estudos que abordam o repertório musical setecentista apresentam propostas analíticas que buscam resgatar uma dimensão histórica não só da escuta, mas também da compreensão desse repertório a partir do jogo discursivo da música, considerando-a como uma das artes da oratória. ${ }^{3}$ Dentre alguns desses principais estudos destacamos as investigações empreendidas por Vasili Byros (Topics and Harmonic Schemata, 2014) e Olga SánchezKisielewska (Interactions between Topics and Schemata, 2016). O suporte desses estudos está no uso articulado de duas teorias: a Teoria Tópica (Topic Theory) e a Teoria das Schemata, ou seja, a teoria que analisa esquemas de contraponto galantes.

Como breve introdução, é importante ressaltar que esses estudos se tornaram possíveis a partir de questionamentos sobre a primazia da Formenlehre ${ }^{4}$ que tiveram início em meados da década de 1980. Sob uma denominação genérica de New Musicology, as então "novas" abordagens tinham como base perspectivas analíticas que levassem em consideração as relações dos processos de composição musical a partir de uma perspectiva histórico-cultural, inclusive numa intersecção com estudos de gênero humano, antropologia cultural etc. Isso possibilitou uma renovação também nos estudos da música do século XVIII, como a apresentada por Leonard Ratner, em Classic Music (1980), e por Robert Gjerdingen, em Music in the Galant Style (2007).

\footnotetext{
3 Cf. BONDS, Mark Evan. Wordless Rhetoric: Musical Form and the Metaphor of the Oration. Cambridge: Harvard University Press, 1991, p. 54: "The rhetorical concept of form continued well into the nineteenth century and was by no means limited solely to didactic treatises. It extended to the aesthetics of music, in writings directed not only toward the aspiring composer but toward the informed listener as well. The successive ordering of a work's individual sections was seen as a function of the manner in which the composer could effectively present a series of ideas to his audience and thereby elicit an intended emotional response."

4 Pode-se considerar que a ideia de uma Formenlehre (Teoria da Forma) começa a ser moldada desde o momento em que críticos e/ou professores de música, como Francesco Galeazzi (1758-1819), Joseph Riepel (1709-1782) e Heinrich Christoph Koch (17491816), observaram que a música apresentava um discurso inteligível a partir da organização de elementos básicos da linguagem musical, como as estruturas fraseológicas e cadenciais. Já no século XIX, a música, antes pensada a partir dos princípios da retórica e da oratória, passou a ser entendida através de uma lógica formal. Assim, principalmente no universo germânico, mas não só, o impulso da sistematização das cadências, iniciado por H. C. Koch, culminou nos estudos das fraseologias, das formas e das questões harmônicas. Podemos destacar os seguintes teóricos como aqueles que formam o cânone da Formenlehre no século XIX: Antonín Reicha, François-Joseph Fétis, Adolf Bernhard Marx, Eduard Hanslick, Moritz Hauptmann, Hugo Riemann, entre outros. Já na primeira metade do século XX foram fundamentais os estudos e labor pedagógico de Richard Stöhr, Arnold Schoenberg e Erwin Ratz. Aliás, considerando o legado da Formenlehre no processo de ensino e interpretação da música Clássico-Romântica, principalmente no que chamamos de tradição schoenberguiana, indicamos a leitura do texto de Jonathan Dunsby \& Arnold Whittal [2010]. Análise Musical na Teoria e na Prática. Trad. Norton Dudeque. Curitiba: Editora UFPR, 2011, p. $67 s$.
} 
Interação entre tópicas musicais e o esquema harmônico le-sol-fi-sol na Missa de Réquiem... Ágata Yozhiyoka Almeida. Diósnio Machado Neto

Nesse contexto, que reivindicava uma maior atenção aos processos criativos e sociocomunicativos da música setecentista, a Teoria Tópica, impulsionada primeiramente por Ratner (1980), ${ }^{5}$ apresentou-se como uma abordagem de pesquisa que, ao explicar questões formais, considerava relevante questões propriamente semânticas. Com isso, Ratner (1980) observou o uso recorrente de campos simbólicos-musicais, que foram denominados por ele como tópicas musicais. Essa foi uma mudança de paradigma significativa, pois, até o início da década de 1960, as relações semânticas da música tanto estavam submersas em considerações sobre as subjetividades dos compositores, como apresentavam-se vinculadas a um entendimento da obra musical como uma espécie de autobiografia. ${ }^{6}$

A base dos estudos tópicos está em considerar que figuras musicais familiares, ou "comuns", a uma determinada audiência eram elementos do capital sonoro simbólico das sociedades onde tinham vigência. Logo, sua legitimidade se dava no uso compartilhado dos modos de escuta.? As tópicas musicais seriam, assim, uma importante ferramenta que se sustenta em questões semânticas, uma vez que favorecem a observação de como se apresenta e se modifica um determinado significado a partir das condições sociais, históricas e culturais que as envolvem.

\footnotetext{
5 Em Classic Music (1980), Ratner apresenta um modelo de análise que parte da compreensão de que elementos musicais formais, como as frases, os períodos e as cadências, ordenam-se a partir de um pensamento retórico, com a finalidade de não quebrar as expectativas de recepção de um ambiente educado para reconhecer as nuances do jogo expressivo das obras musicais. É nesse sentido que ele apresenta, como uma possibilidade de analisar o conteúdo expressivo de certas configurações musicais familiares do século XVIII, o que veio a ser conhecido por teoria tópica (Topic Theory). Através de sua posterior associação com estudos da semiótica musical, sistematizados nos trabalhos de Kofi Agawu (1991; 2009), Raymond Monelle (1992; The Sense of Music, 2000; The Musical Topic, 2006) e Robert Hatten (1994; Interpreting Musical Gestures, Topics, and Tropes, 2004), a teoria tópica se estabeleceu como uma área dos estudos de significação musical.

6 Mark Evan Bonds $(2020,17)$ considera que este fenômeno começou com a música de Beethoven e tornou-se em uma cultura assimilada do público de modo geral, inclusive, e sobretudo, para os ouvintes contemporâneos: "Yet by the middle of the nineteenth century listeners were routinely hearing Beethoven's music as a revelation of his soul, and they regarded his soul, in turn, as the key to understanding his music. Critics eagerly mapped his life onto his works and his works onto his life. This new way of listening, moreover, extended well beyond Beethoven: audiences were now predisposed to hear the music of all composers-particularly their instrumental works-as a personal outpouring of the self, a form of sonic autobiography." Cf. BONDS, Mark Evan. The Beethoven Syndrome: Hearing Music as Autobiography. New York: Oxford University Press, 2020.

7 Cf. MONELLE, Raymond. The Musical Topic: Hunt, Military and Pastoral. Bloomington e Indianapolis: Indiana University Press, 2006, p. 10: "The primary concern of the topic theorist is to give an account of each topic in global terms, showing how it reflects culture and society, not to focus on music alone".
} 
Interação entre tópicas musicais e o esquema harmônico le-sol-fi-sol na Missa de Réquiem... Ágata Yozhiyoka Almeida. Diósnio Machado Neto

Por sua vez, a pesquisa dos esquemas de contraponto (ou schemata) ${ }^{8}$, realizada por Gjerdingen (2007), proporcionou um método para compreender como ocorria a escuta musical galante. Assim, através de uma perspectiva dos esquemas, como padrões recorrentes da sintaxe musical galante, seria possível observar, por exemplo, o modo como esquemas cadenciais sustentavam a estrutura musical e, ao mesmo tempo, o modo como permitiam um jogo de reconhecimento da trama sonora enquanto forma.

Em síntese, podemos afirmar que essas duas vertentes teóricas, esquemas e tópicas, buscavam resgatar, como já afirmamos acima, uma dimensão histórica da escuta, ou seja, se habilitam para observar os modelos sociocomunicativos e os processos criativos da música em determinado contexto histórico. Contudo, as primeiras gerações dos estudos sobre os esquemas de contraponto e sobre as tópicas musicais consideravam que as duas teorias estavam em lados opostos, pois haveria uma relação dicotômica entre sintaxe e semântica musical. Em outras palavras, os estudos dos esquemas de contraponto relacionam-se com uma concepção sintática da música, pois voltam-se à busca pelo uso reiterado de estruturas harmônicas e contrapontísticas comuns à prática composicional no decorrer do século XVIII. As tópicas musicais, por sua vez, se apresentam como uma possibilidade de compreensão dos elementos musicais vinculados ao caráter significativo da música.

É nesse ponto que os estudos realizados por Byros (2014) e Sánchez-Kisielewska (2016) tornam-se relevantes, pois possibilitam interligar os estudos de esquemas a uma perspectiva que se fundamenta sobre o vocabulário expressivo da música galante. Em síntese, ambos os autores observam como determinados esquemas de contraponto, usados como funções formais, também se relacionavam com a construção simbólica determinada pelo discurso musical. É por isso que se pode acrescentar que a compreensão dessas duas vertentes, a das tópicas musicais e a dos

\footnotetext{
8 A palavra schemata refere-se a padrões de contraponto que eram ensinados como prática pedagógica dos conservatórios napolitanos. Gjerdingen (2007) observou que essas estruturas também eram partícipes de um jogo retórico passível de reconhecimento auditivo dentro do ambiente aristocrático-burguês do século XVIII. Na perspectiva desse autor, importa mais compreender o modo como ocorria a escuta galante a partir do reconhecimento e da catalogação dessas estruturas. Gjerdingen (2007, p. 68) não considerava importante o impacto semântico dos esquemas, como pode ser visto nessa afirmação enfática: "Meaning is not easy to observe objectively."
} 
Interação entre tópicas musicais e o esquema harmônico le-sol-fi-sol na Missa de Réquiem... Ágata Yozhiyoka Almeida . Diósnio Machado Neto

esquemas de contraponto, é respaldada a partir de uma dimensão mais ampla do que aquela na qual postulavam os tradicionais estudos advindos da Formenlehre.

Nosso intento aqui se detém no estudo deste problema específico: a interação entre esquemas de contraponto e tópicas musicais, ambientado na questão da temática da morte. Assim, fundamentado no modelo teórico que se insere na discussão da possibilidade semântica dos esquemas musicais, propomo-nos a mostrar como essa interação seria fundamental para a interpretação do complexo jogo significativo presente no discurso musical fúnebre e religioso do ambiente luso-brasileiro.

Cabe dizer que esse interesse central pelo discurso musical fúnebre se justifica por sua associação a cerimônias que estão sujeitas a um denso espaço representacional. Neste texto apresentamos apenas um recorte de uma pesquisa mais ampla, que trata de observar como a música galante da sociedade de corte estabelece uma relação de proximidade com a temática da morte, uma vez que boa parte da sociabilidade do Antigo Regime se dá por intermédio de cerimônias sobre a morte, a começar pela valorização que sua matriz religiosa, o cristianismo, tem pelos cultos fúnebres. A análise musical, nesse contexto, é de fundamental importância, pois revela as estratégias de persuasão que o espetáculo litúrgico usava como modelo de controle social.

Dito isso, consideramos ser necessário, em um primeiro momento e a título de consolidação teórica, visitar alguns argumentos que dialogam com os pontos de tangência e de afastamento entre as tópicas musicais e os esquemas de contraponto. Para isso, discutiremos a ideia de fluxo em cada uma dessas vertentes e apresentaremos, em um segundo momento, o aporte teórico proposto por Byros (2014). Optamos por apresentar o posicionamento desse autor devido tanto à adequação metodológica proporcionada por seu estudo, como pelo contexto utilizado para circunscrever a interação entre o esquema le-sol-fi-sol e a tópica ombra, uma vez que ambos são comuns a obras religiosas de contexto fúnebre. Tratamos de expor a imbricação dos campos 
Interação entre tópicas musicais e o esquema harmônico le-sol-fi-sol na Missa de Réquiem... Ágata Yozhiyoka Almeida. Diósnio Machado Neto

expressivos e estruturais do discurso musical galante a partir da Missa de Réquiem em Mi bemol Maior (1816), de Marcos Portugal, observando esse esquema de contraponto em diversas situações, a saber: (a) em sua relação semântica com o texto; (b) na associação com tópicas específicas e suas consequências no projeto expressivo; e (c) em seu impacto no plano geral das cadências e na estrutura retórica, inclusive apontando o uso de figuras de retórica como parte do projeto expressivo.

É necessário ressaltar ainda que, como aponta António Jorge Marques, em A obra religiosa de Marcos António Portugal (2012), a musicologia luso-brasileira demonstrou-se, por um tempo, omissa à obra religiosa de Marcos Portugal. Dessa forma, este trabalho também contribui para a ampliação dos estudos que têm como objeto central a obra religiosa desse compositor.

\section{0 fluxo e a relação de esquemas de contraponto e tó- picas na música galante}

Para iniciar a discussão, é necessário que examinemos os modos como o termo fluxo é empregado para denominar o forte trânsito de elementos musicais na obra dos compositores galantes. $O$ termo se justifica na natureza da escrita galante, ou seja, é empregado para descrever um processo criativo que se baseia no jogo de elementos musicais contrastantes. Esses elementos musicais (e seus simbolismos), ainda que sejam constantemente misturados, criam discursos a partir de estruturas fixas reconhecíveis pela escuta treinada. Dito de outra forma, podemos empregar o termo fluxo ao tratarmos da música galante porque o processo composicional do repertório desse período depende de uma combinação não só daquilo que constitui o seu vocabulário expressivo (como as tópicas musicais), mas também de cada gestualidade e de sua formação intrínseca (intervalos, métricas, ritmos, timbre). Essas combinações ocorrem de diversas formas: sobrepondo ou superpondo tópicas; fragmentando motivos ou tratando-os como cantus 
Interação entre tópicas musicais e o esquema harmônico le-sol-fi-sol na Missa de Réquiem... Ágata Yozhiyoka Almeida. Diósnio Machado Neto

firmus; jogando com a temporalidade (o devir do elemento indexado) ou com a referencialidade estática (como as citações ou as diversas formas de intertextualidade); entre outros procedimentos.

Ainda que ambas sejam partícipes do jogo expressivo assegurado pela concepção oratória que se impunha à composição setecentista, é necessário que duas ressalvas sejam feitas, uma vez que as tópicas musicais e os esquemas galantes são compreendidos como elementos musicais que transitam e constituem o discurso musical galante. Primeiro, não podemos confundir o caráter fluido da música setecentista com o movimento constitutivo das tópicas musicais. Ao definir as tópicas musicais como "estilos e gêneros musicais retirados de seu contexto apropriado e usados em outro" ${ }^{9}$ Mirka (2014, p. 2, grifos da autora) enfatiza que, para que determinado estilo ou gênero musical passe a ser considerado como um elemento tópico, é preciso que ele se desloque e se misture com outros estilos e gêneros, que também podem estar deslocados de suas funções/representações originais. ${ }^{10}$ Segundo, os esquemas galantes, apresentados por Gjerdingen (2007) como schemata, não carecem de um deslocamento de contextos adequados para se constituírem enquanto tais, pois formam a estrutura sintática da obra musical, como cadências ou pontuações específicas dentro da forma. Sendo assim, elas só se tornam parte do fluxo expressivo de determinada obra quando atuam junto ao elemento semântico.

Nesse sentido, pode-se dizer que os esquemas constituem um problema para uma análise discursiva voltada às questões da significação musical. A começar que eles eram estruturas musicais fixas que eram apreendidas como exercício de harmonização pelos jovens compositores, que as memorizavam pelos partimenti de seus mestres. ${ }^{11}$ Em outras palavras, esse processo se sustentava porque era uma relação de orientação pragmática, em que se

\footnotetext{
9 "musical styles and genres taken out of their proper context and used in another one." (MIRKA, 2014, p. 2, grifos da autora). Doravante, as traduções das citações em língua estrangeira apresentadas neste artigo são de responsabilidade dos autores. 10 Para uma discussão sobre a definição de tópicas musicais, ver Mirka (2014, p. 1-60) e Almeida (2016, p. 71-122).

11 Segundo Gjerdingen (2007, p. 465), partimenti eram baixos instrucionais com objetivo pedagógico em que o aluno, ao dispor de uma linha do baixo a ser executada no teclado com a mão esquerda, deveria apresentar possibilidades de solução e realização com a mão direita. Esse processo composicional fundamentava-se, sobretudo, na assimilação de comportamentos musicais estilisticamente apropriados.
} 
Interação entre tópicas musicais e o esquema harmônico le-sol-fi-sol na Missa de Réquiem... Ágata Yozhiyoka Almeida. Diósnio Machado Neto

transmitiam as especificidades a partir de um conhecimento prático para sustentar a sintaxe musical, e não seu jogo semântico. “É como é" e "faço assim porque sempre se fez assim" seriam formas resumidas de respostas ao "porquê" se compor como se compõe, ou seja, a prática composicional fundamentada sobre esse processo estava atrelada a fórmulas (ou esquemas) exaustivamente praticadas nos conservatórios napolitanos do século XVIII. ${ }^{12}$ Assim, por se tratarem de elementos constitutivos da "gramática musical" e, portanto, passíveis de serem categorizados como uma instância da sintaxe musical setecentista, os esquemas galantes são, no mais das vezes, tidos como elementos semanticamente neutros. Disso resulta o posicionamento de Gjerdingen (2007, p. 120) de que os esquemas seriam adaptáveis a qualquer tópica. Para o autor, os esquemas não são dependentes de parâmetros musicais que são importantes, por exemplo, às tópicas musicais, como: métrica, textura, tempo, dinâmica ou ainda, afetos e gêneros.

Especificamente no domínio das tópicas musicais, SánchezKisielewska (2016) elenca alguns autores, como Monelle (1992) e Agawu (1991; 2009), que, seguindo essa dicotomia, consideram que as tópicas musicais são elementos semânticos. Haveria, por assim dizer, na abordagem de Agawu (1991), fundamentado pelos postulados do linguista Roman Jakobson, uma separação inequívoca entre os eixos semântico-tópico e sintático: “O eixo tópico (extroversivo) cruza com a organização sintática (introversivo) da estrutura musical, mas eles permanecem em última análise independentes e governados por princípios diferentes."13 (SÁNCHEZKISIELEWSKA, 2016, p. 64).

Percebemos com isso que, enquanto a tópica se constitui a partir de um "deslocamento" para cumprir com seu papel semântico, o mesmo não ocorre com os esquemas de contraponto. Logo, por um lado, é possível afirmar que as tópicas adquirem carga

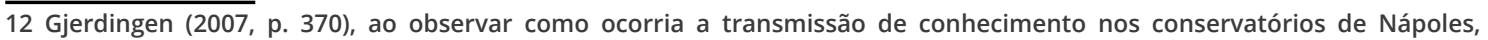
apresenta um persuasivo exemplo, por se tratar de uma resposta de um dos importantes mestres napolitanos de seu tempo, Francesco Durante (1684-1755), a respeito desta questão: “Do it this way because this is the way it is done. It must be this way because the true and the beautiful are one, and in this I am not mistaken. I cannot tell you the reasons that you ask of me, but you may be sure that the maestros who come after me will find them, and of the precepts that I give you now, they will make many axioms that will develop into infallible rules."

13 "the topical (extroversive) axis intersects with the syntactic (introversive) organization of the musical structure, but they remain ultimately independent and governed by different principles." (SÁNCHEZ-KISIELEWSKA, 2016, p. 64).
} 
Interação entre tópicas musicais e o esquema harmônico le-sol-fi-sol na Missa de Réquiem... Ágata Yozhiyoka Almeida . Diósnio Machado Neto

valorativa a partir do uso de estilos e gêneros "fora" de seus contextos adequados (ou seja, deslocados); por outro, os esquemas têm valor independentemente de sua relação semântica. Dessa forma, tratar de misturas ou correspondências fluidas entre os esquemas, seja de forma justaposta ou sobreposta, seria para exemplificar suas transformações, suas apropriações e a infinidade de variações e combinações destes, mediante a ars combinatoria (GJERDINGEN, 2007, p. 115).

Dito isso, reafirmamos com outras palavras o que é fundamental neste texto: demonstrar que o ponto de tangência entre os esquemas de contraponto e as tópicas musicais encontra-se em um processo criativo que necessita de um forte fluxo do material musical para criar as metáforas musicais de sentimentos, paisagens, ações humanas e até ideias abstratas, como o heroico, a abnegação e o trágico-transcendente (HATTEN, 1994). Tal concepção pode ser compreendida na observação de que ambas são adaptáveis à principal característica da música galante: a "plasticidade" semântica dos elementos expressivos. Isso pode ser visto concretamente quando nos deparamos com uma tópica de minueto na ária de uma ópera, em uma missa ou em uma sonata para piano. O mesmo ocorre com os esquemas. Uma Romanesca - esquema originalmente vinculado a danças rústicas - aparece em um sem fim de obras "fora" do ambiente original.

No entanto, a presença desses elementos expressivos por si só não garantia a sua participação em um projeto expressivo. Para que isso ocorresse, era necessário assegurar o seu caráter de adaptabilidade. É deste modo, pela fluidez desses elementos musicais sintáticos e semânticos, combinando-se num todo expressivo, que o discurso musical galante se constituía. Era o fluxo do material musical que garantia a correlação conotativa dos elementos expressivos. Ativar o valor cultural das tópicas, dos esquemas harmônicos e das métricas era uma função da discursividade, ou seja, do projeto de fluência dos materiais combinados em dado discurso musical. 


\section{Interação entre esquemas de contraponto e tópicas musicais}

Ainda que se valham dos estudos de Gjerdingen como fundamentais sobre os esquemas galantes, tanto Byros (2014) como Sánchez-Kisielewska (2016) propõem um outro olhar sobre a neutralidade semântica dos esquemas. Para ambos, tópicas e esquemas podem não só ser considerados de modo afastado, devido à independência ou à autonomia desses dois elementos constitutivos do discurso musical galante, como também podem ser considerados a partir de pontos de tangência. Com relação à primeira consideração, na medida em que se afastam, há a ênfase da independência dos estudos esquemáticos dos tópicos, uma vez que a sintaxe de determinado esquema galante não necessita de sua referência afetiva (no caso, relacionada às tópicas) para que seja entendido. Dito de outra maneira, as expressões afetivas e tópicas, a partir de estilos e gêneros, não são necessárias à sintaxe harmônica (no caso, os esquemas harmônicos) que lhes pode sustentar, o que corrobora a concepção defendida por Gjerdingen.

Entretanto, Byros (2014, p. 381) observa que a autonomia entre tópicas e esquemas subjaz de forma relacional, refletindo uma independência conceitual entre a sintaxe e a semântica musical. Dessa forma, tópicas e esquemas não são fins neles mesmos, pois tangenciam-se na medida em que fazem parte do jogo comunicativo musical de uma sociedade, a galante setecentista, que fundamentava o processo sociocomunicativo sobre bases de reconhecimento de elementos referenciais, como já afirmamos acima (MIRKA, 2008). Sobre isso, Byros (2014, p. 381-382, grifos do autor) afirma:

Tópicas e esquemas harmônicos são combinações de símbolos de estilos musicais que interagem tanto em dimensões sintáticas (sequencialmente estruturadas) como semânticas (referencialmente estruturadas) para algum fim comunicativo e expressivo. Não existem limites nítidos entre elas, seja em termos 
Interação entre tópicas musicais e o esquema harmônico le-sol-fi-sol na Missa de Réquiem... Ágata Yozhiyoka Almeida. Diósnio Machado Neto

categóricos ou pragmáticos. Esta é, em relação à categorização e ao uso da linguagem, a interface sintática e semântica em que os linguistas cognitivos chamam um syntax-lexicon continuum "um continuum de estruturas simbólicas". ${ }^{14}$

A interação, portanto, de tópicas e esquemas potencializa os estudos cuja finalidade seja perscrutar o caráter comunicativo e expressivo do discurso musical galante. Nesse ponto de interação ou de tangência, a aproximação desses elementos ocorre através da combinação de uma dimensão sintática dos esquemas com o suporte expressivo e semântico das tópicas musicais. Assim, ao considerarmos que o discurso musical galante porta elementos comunicativos e expressivos que eram compartilhados e familiares àquela sociedade, tópicas e esquemas podem ser tomados conjuntamente, uma vez que é possível observar interações reiteradas, tal como afirmado por Byros, entre ambas.

Dizemos, corroborando Byros (2014, p. 381), que há, a um só tempo, uma autonomia relacional entre tópicas e esquemas. É relacional, pois ambas aparecem no discurso musical galante em relação, através de suas interações; e trata-se de autonomia, pois podem ser consideradas de forma independente. Assim, não considerar o caráter relacional existente entre tópicas e esquemas ocasionaria certa fragilidade na observação dos processos comunicativos da música do século XVIII.

No texto Topics and Harmonic Schemata (2014), Byros observa como essa interação, ao mesmo tempo autônoma e relacional, ocorre repetidamente entre o esquema le-sol-fi-sol e a tópica ombra. Essa recorrência do amálgama esquema-tópica, "le-sol-fi-sol"-ombra, foi examinada em um grande volume de obras operísticas, instrumentais, e sacras - estas últimas abrangendo obras do período entre 1700 e 1823 (BYROS, 2014). Para o autor, o esquema le-sol-fi-sol não se resume somente a uma estrutura gramatical ou

\footnotetext{
14 "Topics and harmonic schemata are assemblies of musical style symbols that interact in both syntactic (sequentially structured) and semantic (referentially structured) dimensions to some communicative and expressive end. There exist no sharp boundaries between them, either in categorical or pragmatic terms. That is, in respect to both categorization and language use, syntax and semantics interface in what cognitive linguists call a syntax-lexicon continuum - 'a continuum of symbolic structures"'. (BYROS, 2014, p. 381-382, grifos do autor).
} 
Interação entre tópicas musicais e o esquema harmônico le-sol-fi-sol na Missa de Réquiem... Ágata Yozhiyoka Almeida. Diósnio Machado Neto

a uma fórmula de pontuação, por ser um esquema típico de momentos conclusivos ou de fechamento, mas encontra-se carregado semanticamente dos significados propiciados pelo estilo ombra. Esse mesmo procedimento, que combina forma (esquemas) e expressão (tópicas), foi examinado por Sánchez-Kisielewska (2016, p. 65) que observou como o esquema Romanesca, por frequentemente aparecer em contextos sacros, adquiriu a carga semântica da tópica hino-sacro:

Porque a Romanesca aparece frequentemente pareada com o hino, e, também, em contextos sacros, ela adquire significados espirituais [...]. Eu chamo esse amálgama fluido entre sintaxe e semântica musical, uma entidade que não é nem puramente esquemática nem exatamente tópica, de Romanesca sacra. ${ }^{15}$

No caso do le-sol-fi-sol, quando empregado tanto em contextos sacros como teatrais, Byros (2014) observou que sua aparição coincide com elementos textuais relacionados ao funéreo, à mortalidade e ao sobrenatural. Sabemos, a partir dos estudos realizados por Clive McClelland (2012, 2014), que tais elementos são também comuns à significação expressiva do estilo ombra. Esse "amálgama fluido" entre esquema e tópica, especificamente na música litúrgica, pôde ser constatado por Byros (2014, p. 395-6) em momentos relacionados à temática da morte em trechos específicos da missa: no Credo ("Et incarnatus est" e "Crucifixus"), no Agnus Dei ("peccata mundi" e "miserere") e no Glória ("peccata mun$\left.d i^{\prime \prime}\right)$. Ademais, duas missas de réquiem constam em sua listagem, ambas com a ocorrência no trecho "et lux perpetua luceat eis".

Apropriando-nos da contribuição de Byros (2014), mostraremos, a seguir, as ocorrências desse amálgama esquema-tópica encontradas na Missa de Réquiem de Marcos Portugal.

\footnotetext{
15 "Because the Romanesca appears frequently paired with the hymn, and also in sacred contexts, it acquires spiritual meanings [...]. I call this fluid amalgam between musical syntax and semantics, an entity that is neither purely schematic nor exactly topical, the sacred Romanesca." (SÁNCHEZ-KISIELEWSKA, 2016, p. 65).
} 
Interação entre tópicas musicais e o esquema harmônico le-sol-fi-sol na Missa de Réquiem... Ágata Yozhiyoka Almeida. Diósnio Machado Neto

\section{Estudo de caso: Missa de Réquiem de Marcos Portugal}

Marcos António da Fonseca Portugal (1762-1830) foi um notório compositor luso-brasileiro, reconhecido no cenário europeu principalmente por suas obras de gênero dramático. Sua admissão no Seminário da Patriarcal de Lisboa, onde estudou com importantes nomes, como João de Sousa Carvalho e José Joaquim dos Santos, ocorreu em 1771, quando tinha apenas 9 anos de idade. Em 1782, foi nomeado como organista da Santa Igreja da Patriarcal e, nesse mesmo ano, iniciou-se a relação profissional dele com a Família Real Portuguesa através da encomenda de uma Missa com instrumental para a festa de S. Bárbara, a ser cantada na Real Capela de Queluz.

No período de 1782 a 1792, as obras religiosas de Marcos Portugal ganham notoriedade no âmbito das capelas reais. Entre 1792 e 1800, conhecido como seu período italiano, Marcos Portugal estreou cerca de 21 óperas em várias cidades italianas. Ao voltar a Lisboa, em 1800, foi nomeado Mestre de Solfa do Seminário da Patriarcal e Maestro do Real Teatro de S. Carlos, acumulando ainda a função de compositor ao serviço de D. João, então Príncipe Regente. Com a partida da Família Real para o Rio de Janeiro em 1807, por conta da invasão francesa ao Reino de Portugal, Marcos Portugal foi convocado somente em 1810, chegando ao Brasil em 1811.

No Rio de Janeiro, Marcos Portugal não foi nomeado como Mestre da Capela Real, cargo destinado ao Padre José Maurício Nunes Garcia. Formalmente, Marcos Portugal possuía o título de Mestre de Suas Altezas Reais, além do que, dentre um dos motivos pelos quais foi convocado a juntar-se à Família Real, deveria compor músicas destinadas às celebrações de cunho sociopolítico. Foi para uma dessas celebrações que o Príncipe Regente, D. João VI, encomendou a Marcos Portugal uma composição destinada para as exéquias da Rainha D. Maria I, falecida em 1816. A escrita da Missa de Réquiem em Mi bemol maior corrobora a potencialidade da 
Interação entre tópicas musicais e o esquema harmônico le-sol-fi-sol na Missa de Réquiem... Ágata Yozhiyoka Almeida. Diósnio Machado Neto

representação simbólica que as encenações do Poder Real requeriam da música, compreendida como um elemento chave dessa representação.

Consideramos como ponto de partida para a análise aqui proposta, que procura observar a relação de tópicas e esquemas de contraponto na Missa de Réquiem em Mi bemol maior, a observação de algumas singularidades que estimulam a análise discursiva dessa obra de Marcos Portugal. ${ }^{16}$ Uma delas, talvez a mais instigante, é ter sido escrita em uma tonalidade maior, neste caso, em Mi bemol maior. Considerando que a maioria dos réquiens são escritos em tonalidades menores, a tonalidade em maior desse réquiem a tornaria "marcada". ${ }^{17}$ Pretendemos mostrar como Marcos Portugal dominava as práticas composicionais de seu tempo, quer no plano sintático, particularmente o esquemático, quer no projeto expressivo dessa obra.

Como procedimento analítico, em um primeiro momento, buscamos identificar, através do reconhecimento dos padrões de baixo do le-sol-fi-sol, as recorrências desse esquema na totalidade do Réquiem de Marcos Portugal. O le-sol-fi-sol, tal como apresenta Byros (2014, p. 383), é um esquema harmônico que "caracteriza uma virada cromática distintiva da frase no baixo orientado ao redor da dominante, b6-5-\#4-5, com reiterações dos graus I e III da escala nas vozes superiores."18 As características desse esquema encontram-se resumidas na figura abaixo:

\footnotetext{
16 Algumas dessas singularidades foram observadas por Machado Neto (2012), que se propôs a apresentar um estudo preliminar acerca da significação musical dessa obra.

17 Para uma abordagem sobre a teoria da marcação na música, ver HATTEN, 1994.

18 "This pattern features a distinctive chromatic turn of phrase in the bass oriented around the dominant, $\square 6-5-\square 4-5$, with reiterations of scale degrees 1 and 3 in the upper voices." (BYROS, 2014, p. 383).
} 
Interação entre tópicas musicais e o esquema harmônico le-sol-fi-sol na Missa de Réquiem... Ágata Yozhiyoka Almeida. Diósnio Machado Neto

Figura 1. Esquema le-sol-fi-sol: representação abstrata (BYROS, 2014, p. 384).

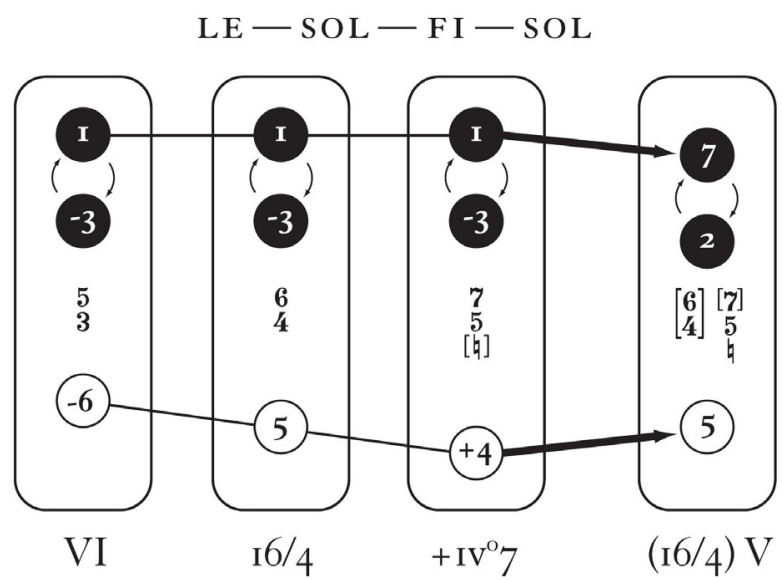

Esse padrão na linha do baixo do le-sol-fi-sol (b6-5-\#4-5) apareceu seis vezes (listados na Tabela 1), sendo que somente em uma das ocorrências aparece em sua forma completa (tal como apresentada na Figura 1).

Consideramos, em um segundo momento, as características da tópica ombra nas recorrências do esquema, constatando que, dentre as seis aparições, essa tópica somente se associou ao le-sol-fi-sol em dois momentos no Domine Jesu Christe. Nas outras quatro ocorrências observamos os parâmetros expressivos de duas outras tópicas, a saber, tempesta e estilo eclesiástico (learned style).

Tabela 1. Esquema le-sol-fi-sol (com suas variações) e tópicas ombra, tempesta e estilo eclesiástico em seções da Missa de Réquiem de Marcos Portugal.

\begin{tabular}{|c|c|c|c|}
\hline Seção & Comp. & Texto & Esquema + Tópica \\
\hline \multicolumn{4}{|l|}{ Sequentia } \\
\hline Dies irae & cc. $33-36$ & "Teste David cum Sibylla" & le-sol-fi-sol + tempesta \\
\hline Juste judex & cc. $30-36$ & "Ante diem rationis" & tempesta + le-sol...fi-sol \\
\hline \multicolumn{4}{|l|}{ Offertorium } \\
\hline \multirow{4}{*}{$\begin{array}{l}\text { Domine Jesu } \\
\text { Christe }\end{array}$} & cc.16-19 & "defunctorum" & le-sol-fi+ estilo eclesiástico \\
\hline & cc. $20-26$ & "de poenis inferni" & fi-sol-le + ombra \\
\hline & cc. $32-35$ & "Libera eas" & $\begin{array}{c}\text { le-sol-fi }+ \text { Morte }(?)+\text { estilo } \\
\text { eclesiástico }\end{array}$ \\
\hline & cc. $37-42$ & "de ore leonis" & fi-sol-le + ombra \\
\hline
\end{tabular}


Interação entre tópicas musicais e o esquema harmônico le-sol-fi-sol na Missa de Réquiem... Ágata Yozhiyoka Almeida. Diósnio Machado Neto

Das duas variações encontradas do esquema, destacamos o movimento cromático e ascendente do baixo, प4-5-46 (fi-sol-le), movimento este que Byros (2014) denomina de via dolorosa, que será mais adiante explorado. Em sua forma "deceptiva", não retornando ao 5 e terminando a descida cromática no $\square 4$ (movimento denominado (e-sol-fi), discutiremos o possível desenvolvimento do esquema Morte que compreende, como apresenta Rice (2015), uma passagem melódica em movimento cromático descendente, no baixo, e ascendente, nas vozes superiores.

Com relação ao plano expressivo, o primeiro aspecto que devemos considerar é a recorrência do le-sol-fi-sol com outras tópicas que não a ombra. No que se diz respeito às tópicas ombra e tempesta, consideramos a proximidade que Clive McClelland (2014) estabelece entre elas. Para esse autor, ambas compartilham elementos lexicais quanto à harmonia, pois se sustentam sobre progressões "surpresas" e cromáticas, bem como do movimento cromático, em grau conjunto, do baixo, sendo o principal elemento de distinção entre elas o andamento: enquanto o estilo ombra está associado a andamentos lentos ou moderados, o estilo tempesta tende a apresentar-se em andamentos rápidos (MCCLELLAND, 2014, p. 282). Essas características que ambas as tópicas compartilham são comuns ao padrão cromático do baixo le-sol-fi-sol (प6-544-5). O estilo eclesiástico, ${ }^{19}$ ou estilo aprendido (learned style), por sua vez, parece corroborar a significação espiritual também presente nas recorrências constatadas do le-sol-fi-sol por Byros (2014).

\subsection{Dies irae e Juste judex}

Um dos problemas instigantes para a relação entre tópicas e esquemas está no Dies irae e no Juste judex. No Réquiem de Marcos

\footnotetext{
19 Esse estilo foi apresentado por Ratner (1980) como a nomenclatura de uma tópica musical que tinha como referência estilos associados à música sacra do século XVIII. No entanto, Keith Chapin (2014) observa que esse termo é um neologismo do século XX. Para Chapin (2014), não há um "estilo eclesiástico", uma vez que é um termo que abarca vários outros "estilos eclesiásticos" e pode ser definido de maneira limitada ou ampla. Assim, se por um lado é definido a partir de sua associação com técnicas contrapontísticas imitativas, como a fuga e os cânones; por outro lado, associa-se a outros estilos considerados "altos" (high styles), como as espécies de contraponto, a polifonia a cappella, o coral e as complexidades harmônicas da fantasia. Resumidamente, alguns elementos musicais que caracterizam este estilo seriam: passagens imitativas (em fugato), suspensões e notas longas (como semibreves). Cf. CHAPIN, Keith. Learned Style and Learned Styles. In: MIRKA, Danuta (ed.). The Oxford Handbook of Topic Theory. New York: Oxford University Press, 2014. p. 301-329.
} 
Interação entre tópicas musicais e o esquema harmônico le-sol-fi-sol na Missa de Réquiem... Ágata Yozhiyoka Almeida . Diósnio Machado Neto

Portugal, ambos não só apresentam elementos textuais comuns, como também usam recursos musicais similares. A primeira consideração, determinante para as escolhas e estratégias da composição, é que textualmente as duas unidades musicais aludem ao advento do Julgamento Final executado por um juiz justo. A ambientação se estabelece a partir dos afetos de temor e inquietação, que se revelam com expressões como "dia de ira", "tremor", "julgar com rigor" e "juiz de justo castigo".

Com relação aos elementos musicais comuns, temos: tonalidade em Ré maior; andamento rápido (allegro maestoso); algumas progressões harmônicas instáveis; notas repetidas no baixo; trêmulos; agitação rítmica; contrastes de dinâmica; e métrica em dáctilo. Com exceção à tonalidade, todos esses elementos são característicos do estilo e de sua referência tópica tempesta, comuns a essa seção dos réquiens (MCCLELLAND, 2014), apesar de estar marcada por sua tonalidade maior (relembramos que a tempesta, em autores do começo do século XVIII, aparecia em modo maior, o que pode significar alguma referencialidade que nos escapa hoje).

Um dos elementos que potencializam a expressividade proporcionada pela tópica tempesta no Dies irae, e que ratifica os indícios desse estilo e recorrência tópica, é a curta passagem em Ré menor que se desencadeia por um movimento cromático na linha do baixo. Nesse movimento, iniciado pelo acorde de Si bemol maior ( $b$ VI de Ré maior), no compasso 33, observamos o desenvolvimento do le-sol-fi-sol, única ocorrência em sua forma completa: b 6-5-\#4-5, no baixo; e reiterações do movimento em grau conjunto, cromático e descendente, dos graus 3-2 e 1-7 no coro e nos instrumentos (ver Ex. 1).

Destacamos o uso desse esquema como o elemento conclusivo que suscita ambiguidade neste momento de transição entre tonalidades, uma vez que serve como progressão tanto da tonalidade de Ré maior como para Ré menor. Essa ambiguidade é enfatizada pela conclusão em uma semicadência no compasso 41, deixando em aberto se a tonicização em Ré menor se efetivará como uma modulação ou se haverá um retorno à tonalidade maior. 
Interação entre tópicas musicais e o esquema harmônico le-sol-fi-sol na Missa de Réquiem... Ágata Yozhiyoka Almeida. Diósnio Machado Neto

Em síntese, poderíamos dizer que ocorre, nessa passagem, uma possível conquista de função sintática e semântica entre tópica e esquema. ${ }^{20}$ Isso porque, como um ponto de modulação para Ré menor, o esquema enfatiza as conotações da tópica tempesta de inquietação, desconforto, tremor e terror.

\section{Ex. 1. Le-sol-fi-sol e tempesta no Dies irae da Missa de Réquiem de Marcos} Portugal, cc. 32-36.

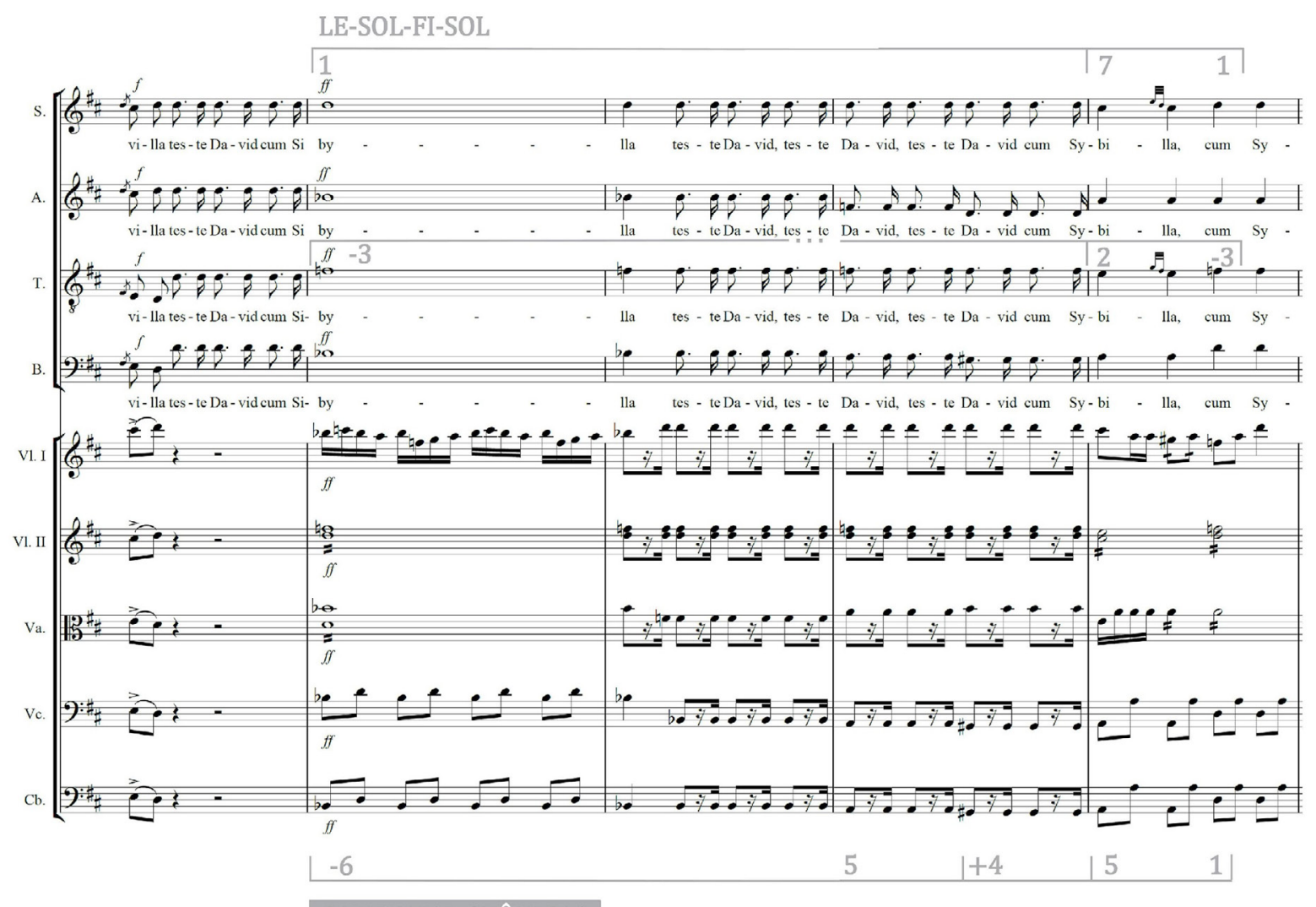

CADENCIAL ( TÔNICA)

Por sua vez, o Juste judex apresenta uma referência ao discurso musical do Dies Irae no trecho em que se clama pela remissão de pecados "diante do dia da razão" (ante diem rationis). Entretanto, apesar de semelhanças com o Dies Irae, não há um espelhamento das estratégias. Isso pode ser observado a partir da interrupção do movimento cromático do baixo, iniciado no acorde de Si bemol

20 Processo observado por Byros (2014, p. 405) na "Eroica", de Beethoven: "the harmonic schema achieves a syntactic and semantic function in one gesture: it produces a modulation to $\mathrm{G}$ minor while introducing a sacred-music reference of sacrificial death, thereby marking the mortal, funereal, sacrificial, and submissive connotations of G minor." 
Interação entre tópicas musicais e o esquema harmônico le-sol-fi-sol na Missa de Réquiem... Ágata Yozhiyoka Almeida. Diósnio Machado Neto

maior no compasso 27, por um acorde de tônica na passagem do segundo para o terceiro estágio do le-sol-fi-sol, que se estabeleceria na passagem do 5-\#4 (ver Ex. 2).

O movimento interrompido do le-sol, após enfatizar a tonalidade Ré maior, apresenta, em seguida, uma progressão harmônica que, por seu motivo cromático ascendente na linha do baixo, \#4-5$\# 5-6$, passa primeiro pela relativa menor da tonalidade (iv) para finalmente concluir o fi-sol, \#4-5, do esquema nos compassos 33-34. Nesse ponto, diga-se de passagem, Marcos Portugal usa figuras de retórica de intensificação (gradatio + epizeuxis), o que justificaria a "partição" do esquema le-sol-fi-sol em decorrência de um acento de eloquência, para amplificar o dizer do ato: "dai-me o dom da remissão, diante do dia da razão".

Ex. 2. Le-sol ... fi-sol no Juste judex da Missa de Réquiem de Marcos Portugal,

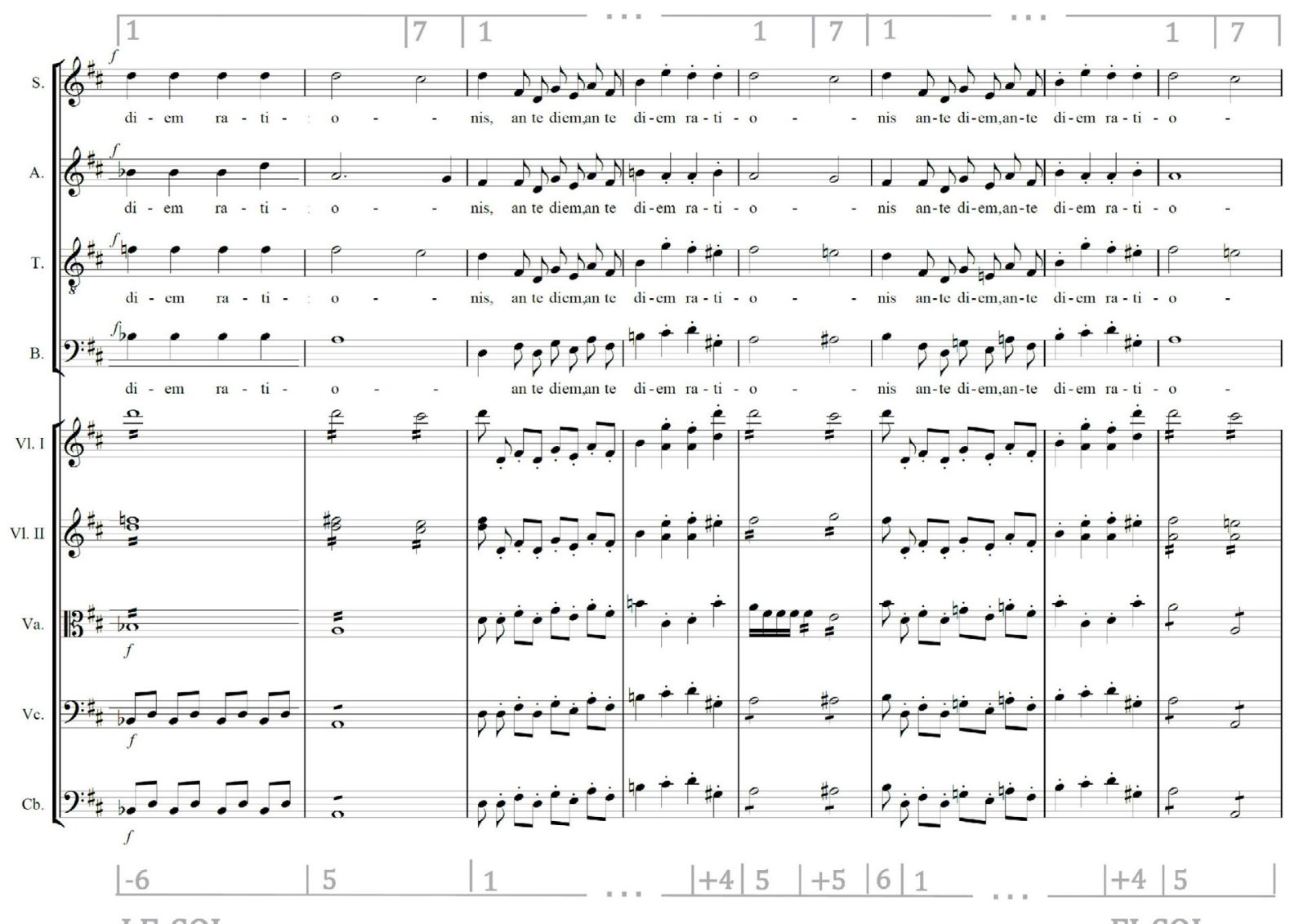


Interação entre tópicas musicais e o esquema harmônico le-sol-fi-sol na Missa de Réquiem... Ágata Yozhiyoka Almeida. Diósnio Machado Neto

Em síntese, podemos dizer que a passagem com harmonias instáveis, gerando certa equivocidade e suspensão de certezas ao enfatizar a tempesta do Dies irae, que leva à tonicização em Ré menor, ocorre diferentemente no Juste judex. Essa diferença pode ser observada a partir da afirmação do ambiente tempestuoso em maior, que rompe com a potencialidade expressiva do le-sol-fi-sol apresentado anteriormente, no Dies Irae.

\section{Domine Jesu Christe}

Dentre todas as seções do Réquiem de Marcos Portugal, o Domine Jesu Christe, que marca o início do Offertorium da missa, pode ser considerado como a seção que apresenta maior contraste tópico (pastoral, tempesta, estilo eclesiástico, ombra) e suscita, portanto, um intenso jogo de significação (ALMEIDA, 2016). Suas referências textuais ao inferno e à escuridão, e o clamor por intervenção da graça divina, são elementos primordiais para a construção do significado expressivo em um contexto fúnebre, enfatizados também pelo uso de figuras retóricas típicas deste contexto, tal como a catabasis (nas expressões "lago profundo", "inferno" e "caiam"). 
Interação entre tópicas musicais e o esquema harmônico le-sol-fi-sol na Missa de Réquiem... Ágata Yozhiyoka Almeida. Diósnio Machado Neto

Ex. 3. Fi-sol-le (passagem em Fá menor) e tópica de ombra no Domine Jesu Christe (de poenis inferni), Offertorium, da Missa de Réquiem de Marcos Portugal, cc. 20-27.

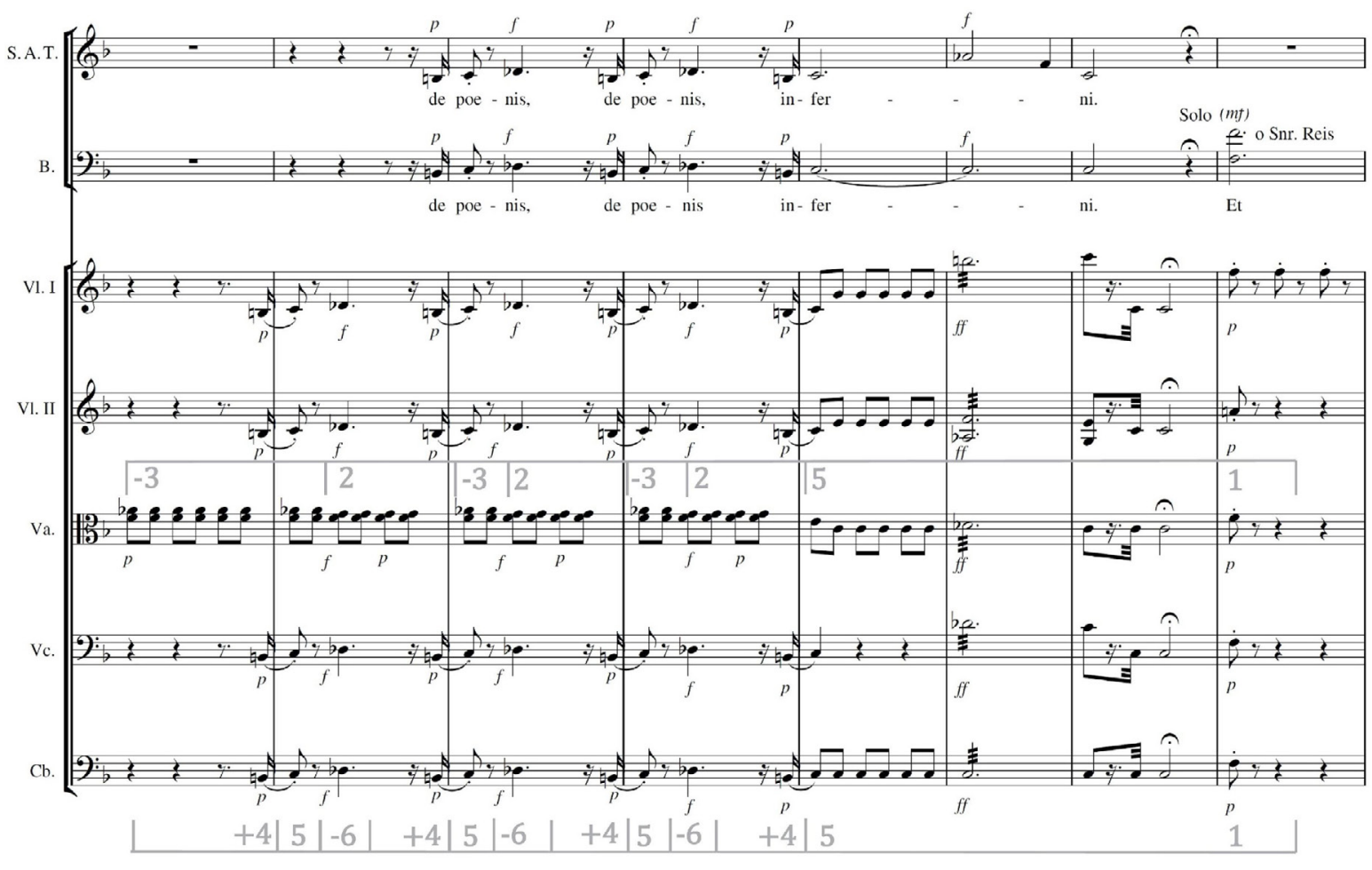

FI-SOL-LE

Em duas passagens podemos observar o uso de uma variante do le-sol-fi-sol, nas quais ocorre o movimento cromático ascendente do baixo com uma inversão do esquema: fi-sol-le, ou \#4-5-b6 (ver Ex. 3 e 4). ${ }^{21}$ No primeiro excerto (Ex. 3), que compreende os compassos 20-27, elementos do amálgama esquema-tópica com a variante fi-sol-le sobrecarregam o caráter sombrio da expressão de poenis inferni ("das penas do inferno"). Dessa forma, ao ressaltar os traços característicos da ombra, como a instabilidade da progressão harmônica, Marcos Portugal sugere uma modulação para Fá menor (a tonalidade desta seção é Fá maior) que não ocorre. Ademais, incrementa a passagem com movimento cromático em

\footnotetext{
21 Byros observa na Sinfonia "Eroica" o uso reiterado e sequencial deste padrão invertido, enfatizando conotações de ombra: "Its ombra connotations are further communicated by an ascending chromatic line in the bass that precedes the cadence, which results from sequential repetitions of a le-sol-fi-sol variant: its inverse, fi-sol-le (प4-5-प6)." (BYROS, 2014, p. 405, grifos do autor).
} 
Interação entre tópicas musicais e o esquema harmônico le-sol-fi-sol na Missa de Réquiem... Ágata Yozhiyoka Almeida. Diósnio Machado Neto

uníssono nas cordas e no coro; mudanças súbitas de dinâmica e acentuação; dentre outras.

O segundo exemplo (Ex. 4) apresenta alguns pontos de maior intensidade expressiva que o primeiro. Isso ocorre principalmente com a suspensão da tonalidade, que sugere uma modulação para a tonalidade de Sol menor, intercalando uma progressão harmônica instável. Isso é escrito com reiterações de sexta aumentada (+6) e do acorde de Sol menor em segunda inversão $(i \% / 4)$, que tem seu gesto conclusivo em uma semicadência.

Ex. 4. Fi-sol-le (passagem em Sol menor) e tópica de ombra no Domine Jesu Christe (de ore leonis), Offertorium, da Missa de Réquiem de Marcos Portugal, cc. 36-43.

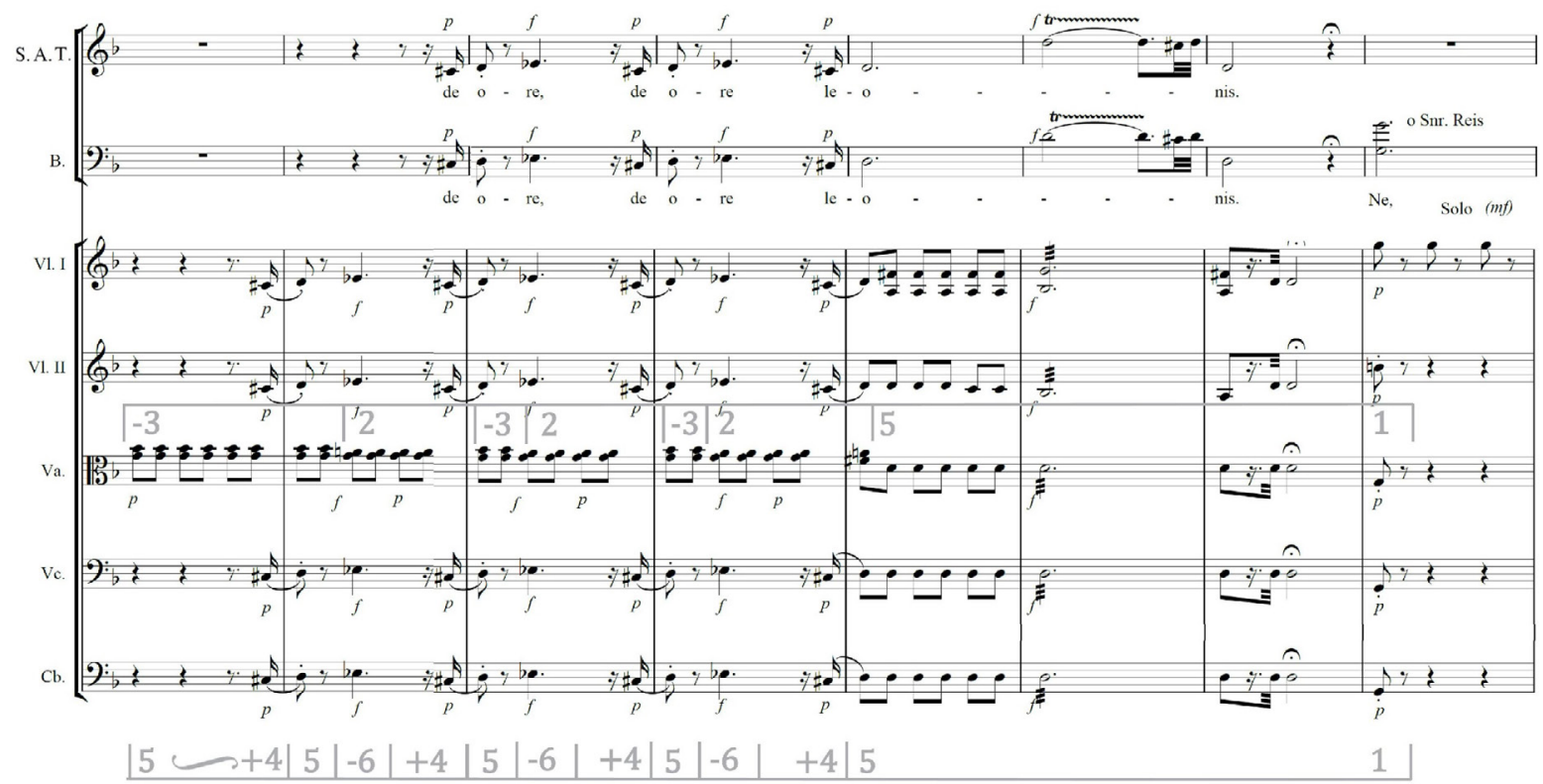

FI-SOL-LE

Cabe mencionar que o movimento cromático ascendente proporcionado pela variante fi-sol-le pode nos remeter à representação da via dolorosa de Cristo, tal como afirma Byros (2014, p. 405, grifos do autor): “No 'Crucifixus' de uma missa, linhas cromáticas ascendentes no baixo são tipicamente usadas para representar a 
Interação entre tópicas musicais e o esquema harmônico le-sol-fi-sol na Missa de Réquiem... Ágata Yozhiyoka Almeida . Diósnio Machado Neto

via dolorosa de Cristo, como no 'Crucifixus' da Missa da 'Coroação', de Mozart, e da Missa 'Harmonia' em Si bemol maior, de Haydn." ${ }^{22}$

Assim, é significativo que o movimento cromático ascendente destas duas passagens do Domine Jesu Christe, característico da via dolorosa e, portanto, relacionado à trajetória dolorosa, mas transcendente, de Cristo, não complete o movimento que assinala esta transcendência. Não se trata da via dolorosa de Cristo, mas do homem preso em um movimento que expressa, através dos intervalos cromáticos que se repetem, a intensificação a dor.

Os quatro compassos que antecedem as duas realizações da variante fi-sol-le apresentam outra variante, o le-sol-fi (b6-5-\#4). ${ }^{23}$ Dessa vez, a linha cromática do baixo se caracteriza pela ausência do sol final, apresentando um cromatismo descendente. A entrada do coro em tutti e a cappella, logo após passagens de solo, são traços do estilo eclesiástico. Nesse contexto, observamos tanto sobre a palavras defunctorum ("defuntos", ver Ex. 5), como libera eas ("libera-as", ver Ex. 6), a sobreposição da variante le-sol-fi em estilo eclesiástico prenunciando as passagens em ombra que se seguem (Ex. 3 e 4). O movimento da linha do baixo parece se constituir da fusão do tetracorde frígio, 1-b7-b6-5, e do primeiro ao terceiro estágios do le-sol-fi-sol, b6-5- \#4.

A inflexão frígia, que constitui ambas as passagens, é considerada como um importante índice de representação da morte na música. Kimmel (1980) observa como no Crucifixus da Missa Solemnis, de Beethoven, no trecho et sepultus est, ocorre o uso do tetracorde frígio. Significando a morte e o movimento descendente (catabasis) para a tumba, é possível observar a precisão do emprego desse tetracorde sobre a palavra defunctorum no Ex. 5. Além disso, como o semitom descendente entre b6-5 é "o ponto crucial da inflexão frígia"24 (KIMMEL, 1980, p. 55), seu prolongamento cromático através do \#4 enfatiza a tragicidade deste trecho, o que justifica o emprego eloquente desse esquema harmônico. Além

\footnotetext{
22 "In the 'Crucifixus' of a Mass, ascending chromatic bass lines are typically used to represent Christ's via dolorosa, as in the 'Crucifixus' of Mozart's 'Coronation' Mass and of Haydn's 'Harmony' Mass in B flat major." (BYROS, 2014, p. 405, grifos do autor). 23 Para uma discussão sobre a variante le-sol-fi, ver BYROS, Vasili. Meyer's Anvil: Revisiting the Schema Concept. Music Analysis, v. 31, n. 3, p. 273-346, 2012. Disponível em: http://www.jstor.org/stable/41811603. Acesso em: 01 jul. 2019.

24 "the crux of the Phrygian Inflection." (KIMMEL, 1980, p. 55).
} 
Interação entre tópicas musicais e o esquema harmônico le-sol-fi-sol na Missa de Réquiem... Ágata Yozhiyoka Almeida. Diósnio Machado Neto

disso, o fluxo melódico dos compassos 16-19 não apresenta a descida das vozes superiores em décimas paralelas, tal como descrito por Gjerdingen (2007, p. 165), mas podemos observar, em contrapartida, o b3 do le-sol-fi-sol que passa do tenor (compasso 17) para o soprano (compassos 18-19) sobre o baixo da variante le-sol-fi.

Ex. 5. Le-sol-fi-sol (variação) e estilo eclesiástico do Domine Jesu Christe na palavra defunctorum, cc. 15-19.

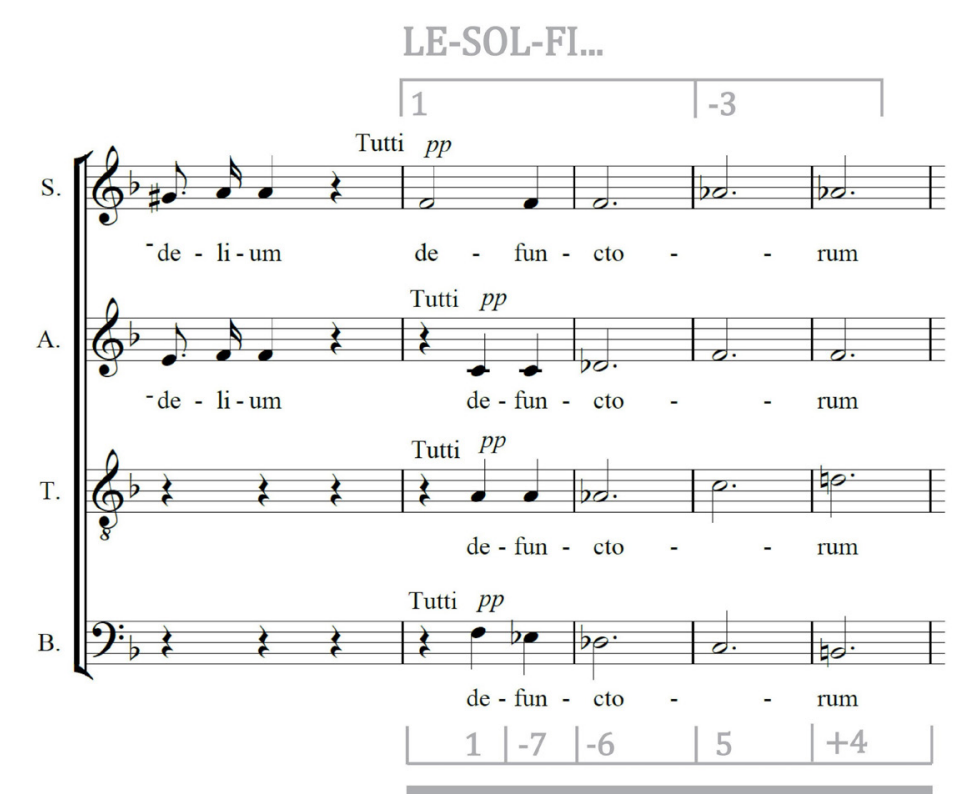

CADENCIAL ( DECEPTIVA) 
Interação entre tópicas musicais e o esquema harmônico le-sol-fi-sol na Missa de Réquiem... Ágata Yozhiyoka Almeida. Diósnio Machado Neto

Ex. 6. Le-sol-fi-sol (variação) e estilo eclesiástico do Domine Jesu Christe nas palavras libera eas, com modulação para Sol menor e possível esquema Morte, cc. 31-35.

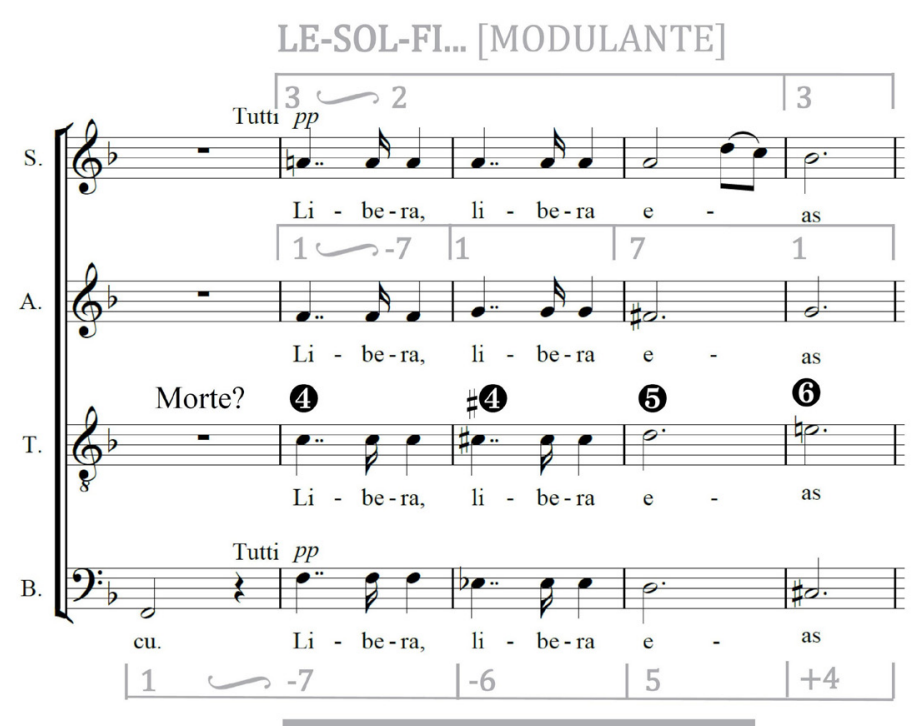

CADENCIAL ( DECEPTIVA)

Neste ponto, ressaltamos a relação dúbia sobre quais esquemas estariam presentes no segundo trecho, dos compassos 3235 (Ex. 6). Assim, se por um lado podemos sustentar nosso argumento de que, neste trecho, temos o uso do tetracorde frígio e da variante le-sol-fi sobre a linha melódica do baixo, bem como o prolongamento desta com o \#4 e o b3 na melodia; por outro, certos elementos musicais, como a presença de uma sexta aumentada na progressão harmônica, e a presença de elementos melódicos não característicos do le-sol-fi-sol, abrem indagações. Isso porque alguns aspectos melódicos, principalmente o início cromático ascendente da linha do tenor (4-\#4-5-6) juntamente à linha do baixo, parecem nos sugerir uma variação reduzida do esquema Morte de cinco estágios: 1-b7-6-b6-5, no baixo (sem a sensível); b3-3-4- \#4-5 nas vozes superiores. Porém, tal como definido por Rice (2015, p. 160), o esquema Morte era considerado "como um intensivo gesto expressivo que poderia efetivamente realçar os momentos mais trágicos de uma obra, mas também como um elemento 
Interação entre tópicas musicais e o esquema harmônico le-sol-fi-sol na Missa de Réquiem... Ágata Yozhiyoka Almeida. Diósnio Machado Neto

composicional fundamental", 25 pois ornamenta passagens de transição através de uma semicadência. Assim, apesar da configuração de linhas cromáticas divergentes e do acorde de sexta aumentada associarem-se frequentemente à tristeza, à tragédia e à morte, Rice (2015) ressalta que este esquema nem sempre está associado à morte ou ao luto.

Portanto, a contingência de associação com a morte ou com o luto nos possibilita estabelecer uma relação interpretativa com os apontamentos feitos por Machado Neto (2017) sobre os compassos finais que constituem a peroração da Sinfonia Fúnebre (1790), de José Maurício Nunes Garcia. Um dos elementos de destaque expressivo é a presença do estilo eclesiástico conjugado com o movimento cromático ascendente, que caracteriza, segundo Machado Neto (2017, p. 59), a bem-aventurança, ou “um gesto de afirmação de que a morte é um problema da Igreja". Desta forma, enquanto a linha cromática descendente caracteriza o lamento como um elemento expressivo do ambiente retórico da pathopoeia, relacionando-se, portanto, com figuras retóricas tais como a catabasis e o passus duriusculus; a inversão deste cromatismo, que se apresenta em ascensão, pode ser considerada não só como um embelezamento, mas como um recurso para modificar a carga semântica do movimento cromático: não mais um lamento, mas uma bem-aventurança.

No caso do trecho do Réquiem de Marcos Portugal (Ex. 6), é percebido, sintaticamente, como um ponto de modulação que faz a transição entre a tonalidade de Fá maior para Sol Maior através de um trecho que toniciza a tonalidade de Sol menor. Com relação à sua significação semântica, apesar de apresentar a tópica em estilo eclesiástico e a gestualidade cromática ascendente que caracterizaria a bem-aventurança, tal como na Sinfonia Fúnebre de Nunes Garcia, sua carga expressiva deve considerar o movimento conjunto das linhas cromáticas divergentes. Assim, ainda que este trecho esteja associado à morte, as palavras libera eas suscitam uma interpretação que se dá na conjugação do movimento

25 "as an intensely expressive gesture that could effectively enhance the most tragic moments of a work, but also as a compositional building-block." (RICE, 2015, p. 160). 
Interação entre tópicas musicais e o esquema harmônico le-sol-fi-sol na Missa de Réquiem... Ágata Yozhiyoka Almeida. Diósnio Machado Neto

contrário e divergente de vida-morte, ou morte-vida: enquanto os fiéis esperam a libertação de seu sofrimento (movimento de morte, descendente e cromático), esta liberdade não se dá senão pela intervenção da graça divina, caracterizada pela ascensão dolorosa de seu Domine Jesu Christe (movimento para a vida eterna, ascendente e cromático).

\section{Considerações Finais}

Observar o modo como Marcos Portugal utilizou elementos expressivos e semânticos (tópicas musicais), conjuntamente ao esquema de contraponto le-sol-fi-sol, permite-nos apontar algumas considerações. Primeiro, é notável a adaptabilidade do esquema le-sol-fi-sol com as referências tópicas dos estilos ombra, tempesta e eclesiástico, bem como a intensificação das estruturas expressivas sobre a morte mediante a manipulação de suas interações a partir de diversas variantes desse esquema. Diante disso, considera-se que a ampliação do estudo e de análises que tenham como objetivo observar esse tipo de interação proposta por Byros (2014) e Sánchez-Kisielewska (2016) se faz necessária para que se possa revelar o domínio que os compositores luso-brasileiros tinham tanto do trato expressivo dos elementos semântico-musicais em contextos fúnebres, como dos esquemas de contraponto que se associam a essas configurações expressivas.

A segunda consideração recai no crescente número de estudos acerca dos esquemas de contraponto na música colonial brasileira. Dentre eles, aqueles desenvolvidos por Páscoa e Monteiro (2018), que observam as recorrências de vários esquemas, inclusive do le-sol-fi-sol, nos Responsórios Fúnebres de João de Deus de Castro Lobo, e por Hartmann (2018), que encontra o esquema Morte na Sinfonia Fúnebre de José Maurício Nunes Garcia, asseguram a influência do método napolitano dos partimenti na prática composicional luso-brasileira. Ainda assim, reconhecemos que, apesar do possível emprego do esquema Morte, observado tanto 
Interação entre tópicas musicais e o esquema harmônico le-sol-fi-sol na Missa de Réquiem... Ágata Yozhiyoka Almeida. Diósnio Machado Neto

na obra citada de José Maurício Nunes Garcia como no Domine Jesu Christe do Réquiem de Marcos Portugal, são poucas as pesquisas que consolidam esse esquema de contraponto.

Diante disso, estudos mais massivos, ainda na obra de Marcos Portugal e de compositores coevos, como José Maurício Nunes Garcia, são necessários para comprovar, por um lado, o uso e as recorrências dos esquemas de contraponto em suas obras. Por outro, deve-se apostar na investigação que se atenha a minuciar a existência, ou não, de recursos retóricos consolidados, ou maneirismos, diante de problemas expressivos específicos, como aqueles relacionados ao contexto musical fúnebre.

\section{Referências}

AGAWU, Kofi. Playing with Signs: A Semiotic Interpretation of Classic Music. Princeton: Princeton University Press, 1991.

AGAWU, Kofi. Music as Discourse. New York: Oxford University Press, 2009.

ALMEIDA, Á. Y. Música, religião e morte: recorrências tópicas na missa de réquiem em Mi bemol maior de Marcos Portugal. 2016. Dissertação (Mestrado em Musicologia) - Escola de Comunicações e Artes, Universidade de São Paulo, São Paulo, 2016. Disponível em: https:// www.teses.usp.br/teses/disponiveis/27/27157/tde-15032017-152743/ pt-br.php. Acesso em: 14 out. 2016.

BYROS, Vasili. Topics and Harmonic Schemata: A Case from Beethoven. In: MIRKA, Danuta (ed.). The Oxford Handbook of Topic Theory. New York: Oxford University Press, 2014. p. 381-414.

GJERDINGEN, Robert O. Music in the Galant Style. New York: Oxford University Press, 2007.

HARTMANN, E. A Sinfonia Fúnebre (1790) do Padre José Maurício Nunes Garcia (1767-1830): análise com o conceito de Schema Musical de Robert Gjerdingen. In: RIBEIRO, Antonio Celso, COSTA, 
Interação entre tópicas musicais e o esquema harmônico le-sol-fi-sol na Missa de Réquiem... Ágata Yozhiyoka Almeida. Diósnio Machado Neto

Ricardo da (org.). Mirabilia, v. 27, p. 221-253, 2018. Disponível em: https://www.revistamirabilia.com/sites/default/files/pdfs/27.09.pdf. Acesso em: 06 abr. 2019.

HATTEN, Robert S. Musical Meaning in Beethoven: Markedness, Correlation, and Interpretation Advances in Semiotics.

Bloomington \& Indianapolis: Indiana University Press, 1994.

KIMMEL, William. The Phrygian Inflection and the Appearances of Death in Music. College Music Symposium, v. 20, n. 2, p. 42-76, 1980. Disponível em: https://www.jstor.org/stable/40374079. Acesso em: 12 abr. 2019.

MACHADO NETO, Diósnio. O discurso musical no Requiem através de um estudo comparativo das tópicas: circunstâncias históricas e contextos estilísticos. In: CRANMER, David. (ed.). Marcos Portugal: uma reavaliação. Lisboa: Colibri, 2012. p. 379395.

MACHADO NETO, Diósnio. A arte do bem morrer: O discurso tópico na Sinfonia Fúnebre de José Maurício Nunes Garcia.

Revista Portuguesa de Musicologia, v. 4, n. 1, p. 33-66, 2017. Disponível em: http://rpm-ns.pt/index.php/rpm/article/view/311/526. Acesso em: 28 set. 2019.

MARQUES, António Jorge Marques. A obra religiosa de Marcos António Portugal (1762-1830): catálogo temático, crítica de fontes e de texto, proposta de cronologia. Lisboa: Biblioteca Nacional de Portugal Centro de Estudos de Sociologia e Estética Musical (CESEM), 2012.

MCCLELLAND, Clive. Ombra: Supernatural Music in Eighteenth Century. Lanham, UK: Lexington Books, 2012.

MCCLELLAND, Clive. Ombra and Tempesta. In: MIRKA, Danuta (ed.). The Oxford Handbook of Topic Theory. New York: Oxford University Press, 2014. p. 279-300.

MIRKA, Danuta. Introduction. In: MIRKA, Danuta; AGAWU, Kofi (ed.). Communication in Eighteenth-Century Music. Cambridge: Cambridge University Press, 2008. p. 1-10. 
Interação entre tópicas musicais e o esquema harmônico le-sol-fi-sol na Missa de Réquiem... Ágata Yozhiyoka Almeida. Diósnio Machado Neto

MIRKA, Danuta. Introduction. In: MIRKA, Danuta (ed.). The Oxford Handbook of Topic Theory. New York: Oxford University Press, 2014. p. 1-60.

MONELLE, Raymond. Linguistics and Semiotics of Music. Londres: Harwood Academic Publishers, 1992.

PÁSCOA, M. L. F. R.; MONTEIRO, G. A. S. Os esquemas de contraponto na música brasileira do Antigo Regime: o caso dos 6 Responsórios Fúnebres de João de Deus de Castro Lobo. Revista Música Hodie, Goiânia, v. 18, n. 2, p. 196-212, 2018. Disponível em: https://www.revistas.ufg.br/musica/article/view/51175/26763. Acesso em: 06 abr. 2019.

PORTUGAL, Marcos. Missa de Mortos: Com todo o instrumental para se executar na Real Capella do Rio de Jan. ${ }^{\circ}$ no dia 23 de Abril. Rio de Janeiro, 28 mar. 1816. Antonio Campos Monteiro Neto, 2007. 1 partitura. Coro e solistas S, A, T, B; orquestra. Disponível em: http://www1.cpdl.org/wiki/index.php/Requiem_ (Marcos_Portugal). Acesso em: 12 mar. 2013.

RATNER, Leonard G. Classic Music: Expression, Form, and Style. New York: Macmillan Publishing Co. Inc., 1980.

RICE, John A. The Morte: A Galant Voice-Leading Schema as Emblem of Lament and Compositional Building-Block.

Eighteenth Century Music, [s.I.], v. 12, n. 2, p. 157-181, ago. 2015 Cambridge University Press (CUP). Disponível em: http://dx.doi. org/10.1017/s1478570615000287. Acesso em: 08 abr. 2019.

SANCHÉZ-KISIELEWSKA, Olga. Interactions between Topics and Schemata: The Case of the Sacred Romanesca. Theory and Practice, v. 41, p. 47-80, 2016. Disponível em: https://www.jstor. org/stable/26477756. Acesso em: 23 jul. 2020. 